\title{
Creation of New Flower Colors in Ornithogalum Via Interspecific Hybridization
}

\author{
R.J. Griesbach \\ United States Department of Agriculture, Agriculture Research Service, Florist and Nursery Crops \\ Laboratory, Beltsville, MD 20705-2350
}

F. Meyer and H. Koopowitz

University of California, Irvine Arboretum, Irvine, CA 92717

Additional index words. embryo rescue, breeding, pot-plant, carotenoids

\begin{abstract}
Embryo rescue was successfully applied to develop hybrids between Ornithogalum dubium Houtt. (short inflorescence with orange flowers) and $O$. thyrsoides Jacq. (tall inflorescences with white flowers]. Meiosis in these hybrids showed abnormalities such as univalents, laggards, and bridges. The $\mathrm{F}$, hybrids were partially fertile, and $\mathrm{F}_{2}$ and $\mathbf{B C}_{1}$ progeny were produced. The backcross hybrids segregated for flower color and, inflorescence traits and introgressed seedlings with orange pigmented flowers on tall inflorescences were obtained in the population.
\end{abstract}

Several Ornithogalum species produce long lasting cut flowers and are commercially grown in the United States and Europe. The most commonly grown species is $O$. thyrsoides, characterized by a tall 20 to $90 \mathrm{~cm}$ long raceme with a tight cluster (short pedicels) of between 10 to 70 flowers, 3 to $5 \mathrm{~cm}$ in diameter. The perianth is yellow-white to white with a dark greenish or brown center that fades with age (Obermeyer, 1978; R.D. Pienaar, personal communication). Another species, O. dubium, is noted for its bright yellow to deep orange-pigmented flowers. There is also a form with white flowers. The colored form of $O$. dubium produces a short 10 to 25 $\mathrm{cm}$ long raceme with a loose cluster (long pedicels) of between 5 and 25 flowers, 2 to $3 \mathrm{~cm}$ in diameter. The white form of $O$. dubium (formerly known as $O$. alticolum) is taller (up to $70 \mathrm{~cm}$ ) and often confused with $O$. thyrsoides (Obermeyer, 1978; R.D. Pienaar, personal communication).

Our goal was to extend the color spectrum of the commercial cut-flower types and to develop new pot-plant forms through interspecific hybridization of $O$. dubium and $O$. thyrsoides. The initial crosses were consistent with those of Pienaar (1963) and Van Niekerk and Pienaar (1968) who found that the interspecific crosses between most of these two species did not produce mature viable seed. This paper describes the use of in vitro, ovule-rescue in obtaining interspecific hybrids and the carotenoid analysis of their flowers.

\section{Materials and Methods}

Reciprocal intra- and interspecific crosses were made between various morphologically distinct forms of Ornithogalum dubium and $O$. thyrsoides. Two forms of $O$. thyrsoides were used: one was from the Clanwilliam area of South Africa (U.C.I. 4230) and the other was a commercial cut-flower clone from the Hadeco Company, South Africa. Ornithogalum thyrsoides 4230 (RHS Colour Chart no. 155D) has whiter flowers with a less intense green/brown center than the Hadeco clone (RHS 155C). Three forms of $O$. dubium were used: one form was from the Plettenberg Bay area (U.C.I. 4745) and the other two from the florist trade without

Received for publication 25 June 1992. Accepted for publication 21 Sept. 1992. We would like to acknowledge the technical support of Ronald Beck and the help of R.C. Jackson and R.D. Pienaar in critically reviewing the manuscript. The cost of publishing this paper was defrayed in part by the payment of page charges. Under postal regulations, this paper therefore must be hereby marked advertisement solely to indicate this fact. collection data (U.C.I. 0519, 5672). Ornithogalum dubium 0519 produces the shortest inflorescence with orange flowers (RI-IS 24A). Ornithogalum dubium 4745 produces bright yellow flowers (RHS 7A) and O. dubium 5672 produces dark orange flowers (RHS 28A). All clones are in the collection at the Arboretum at the Univ. of California, Irvine (U.C.I.).

Because mature, viable seed could not be obtained from the interspecific crosses, all seedlings were produced via ovule rescue techniques. Developing ovaries were harvested 10 to 14 days after pollination and disinfected in $30 \%$ bleach for $20 \mathrm{~min}$. The ovules were then aseptically removed and placed on a medium containing half-strength Murashige and Skoog (MS) (1962) salts and full strength sugars (30 g sucrose/liter) and vitamins solidified with 8 $\mathrm{g}$ agar/liter. All cultures were maintained at $25 \mathrm{C}$ with $16 \mathrm{~h}$ of 260 $\mu_{\mathrm{mol}}{ }^{-1} \cdot \mathrm{m}^{-2}$ cool-white fluorescent illumination. The immature seeds germinated within 2 weeks, producing seedlings large enough to be removed from culture after 3 months. The seedlings were acclimated in a greenhouse and flowered within 1 year.

Specific clones were propagated via leaf tissue culture. Mature but nonsenescent leaves were harvested from plants before flowering and disinfected in $20 \%$ bleach for $20 \mathrm{~min}$, rinsed twice in sterile water, and cut into $2 \times 1 \mathrm{~cm}$ sections. The leaf pieces were placed flat on a medium containing full strength MS salts, vitamins, and sugar supplemented with $1 \mathrm{mg}$ benzylaminopurine (BA)/liter. Within 3 weeks, five to 20 bulbous plantlets developed at the cut surfaces. These plantlets continued to proliferate through off-shoots and were rooted on a hormone-free MS medium.

Pollen and chromosomes from both meiotic and mitotic cells were examined using standard acetocarmine techniques (McClintock, 1929).

Carotenoid flower pigments were analyzed using high pressure liquid chromatography. Single flowers were ground in $25 \mathrm{ml}$ of acetone and filtered through Whatman \#3 paper. The solution was then extracted three times with petroleum ether with $10 \mathrm{ml}$ used each time. The carotenoid-containing ether was dried under reduced pressure by rotary evaporation. The carotenoids were separated as described by Braumann and Grimme (1981) using a $\mathrm{C}_{18}$ column and a 20 min linear gradient of $75 \%$ to $100 \%(\mathrm{v} / \mathrm{v})$ acetylnitrile/methanol (25:75) in water. The solvent was then kept at $100 \%$ for an additional $20 \mathrm{~min}$. The elutant was monitored at 445 $\mathrm{nm}$ with a flow rate of $1.5 \mathrm{ml} \cdot \mathrm{min}^{-1}$.

Plower color also was judged according to the Royal Horticultural Society (RHS) Colour Chart. 


\section{Results}

An average of 10 seedlings each from 40 different crosses were raised to maturity and flowered. Thirty-one of these crosses involvedinterspecific hybrids consisting of $31 \mathrm{~F}_{1}, 11 \mathrm{BC}_{1}$, and $7 \mathrm{~F}_{2}$. Of nine intraspecific crosses, $5 \mathrm{~F}_{1}, 3 \mathrm{BC}_{1}$, and $1 \mathrm{G}_{2}$ were produced. Even though mature seed could be produced from intraspecific crosses, ovule rescue shortened the time to flowering. Seedlings grown from mature seed required at least two seasons of growth or two years before they were old enough to flower, while seedlings grown from ovule-rescue flowered during their first season of growth. Both, the intra- and interspecific crosses produced seedlings exhibiting exceptional vigor, more robust growth than either parent, and early and continuous flowering.

The intraspecific hybrids were fertile and exhibited a normal meiosis with six bivalents and no bridges (Fig. 1). Partially fertile interspecific hybrids between $O$. dubium and $O$. thyrsoides were obtained. Acentric fragments and bridges were observed in close to $40 \%$ of the cells (Fig. 2B).

The karyotype of both $O$. thyrsoides and $O$. dubium consisted of five pairs of long chromosomes (L) and one pair of short chromosomes (S) (Fig. 1A). In the F, hybrid, all the L-chromosomes of $O$. dubium paired with their $O$. thyrsoides homeologues. However, the S-chromosome homeologues rarely paired. In only $2 \%$ of the meiocytes was a S-chromosome bivalent observed (Figs.
$2 \mathrm{C}$ and $4 \mathrm{E})$. Table 1 shows the frequency of various meiotic associations.

The $O$. thyrsoides perianth did not contain any carotenoid pigments but did have a small amount of chlorophyll located in its base. However, the $O$. dubium perianth contained carotenoids and chlorophyll. About $35 \%$ of the $445 \mathrm{~nm}$ absorption in this species was due to chlorophyll. In addition, six carotenoid pigments were found in O. dubium flowers (Table 2). Two of these carotenoids (retention times of 21 and $29 \mathrm{~min}$ ) accounted for nearly three quarters of the total absorption.

Ornithogalum dubium produced flowers that ranged from yellow (clone 4745) to orange (clone 0519). Yellow flowers (RHS 7A) contained almost equal concentrations of the two main carotenoids, while orange flowers (RHS 24A) contained nearly four times as much carotenoid 21. Intraspecific hybrids of $O$. dubium $(0519 \times 4745)$ were yellow-flowered and segregated for yellow and orange pigments. No clear segregation patterns could be discerned.

Primary hybrids between $O$. thyrsoides and $O$. dubium produced flowers that were either light yellow (RHS 11C) or light orange (RHS 14D), depending upon the clone of $O$. thyrsoides used. Crosses involving the Hadeco clone produced hybrids with light yellow to cream-pigmented flowers, containing nearly equal amounts of chlorophyll and carotenoids. When clone 4230 was used, the hybrids were light-orange to pale-gold and contained

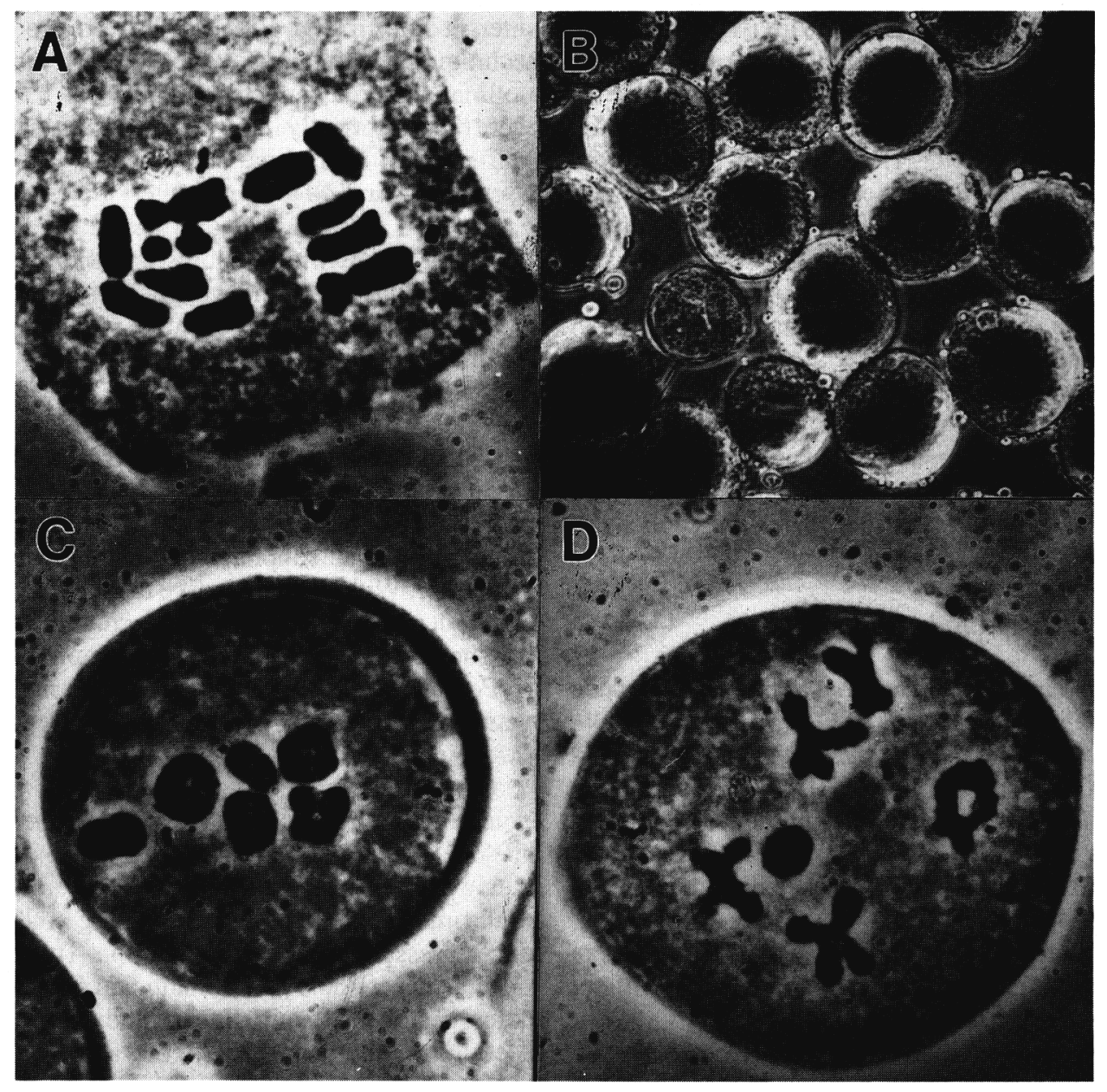

Fig. 1. Meiosis in an interspecific hybrid of Ornithogalum dubium ( $0519 \times 4745)$ : (A) Somatic chromosomes $2 \mathrm{n}=2 \mathrm{x}=10$ long chromosomes +2 short chromosomes. (B) Mature pollen showing $100 \%$ viability. (C) Metaphase I showing six bivalents. (D) Diakinesis showing five bivalent L-chromosomes and one bivalent Schromosome. 


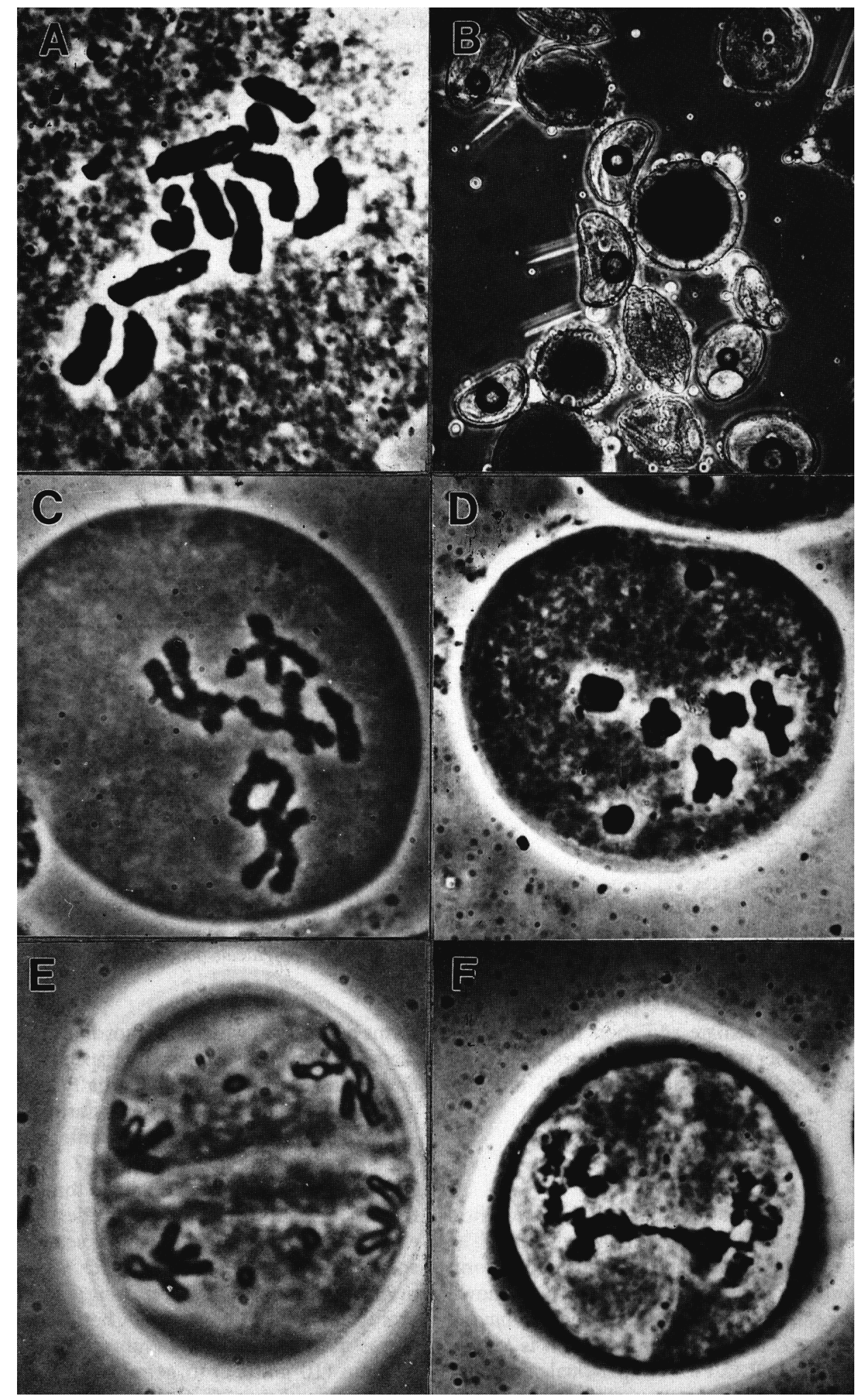

Fig. 2. Meiosis in the F, hybrid between Ornithogalum dubium (0519) and O. thyrsoides (4230): (A) Somatic chromosomes $2 \mathrm{n}=2 \mathrm{x}=10$ long chromosomes + two short chromosomes. (B) Mature pollen showing 30\% viability. (C) Diakinesis showing five bivalent L-chromosomes and one bivalent S-chromosome. (D) Metaphase I showing five bivalent L-chromosomes and two univalent S-chromosomes. (E) Anaphase II showing several acentric fragments. (F) Anaphase I showing a bridge.

almost twice as much carotenoids as chlorophyll.

Backcross hybrids of the $\mathrm{F}_{1}$ to $O$. dubium produced flowers near white (RHS 155D) to dark orange (RHS 28A) (Fig. 3). New intermediate colors such as butter-yellow (RHS 8B) and apricotorange (RHS 24B) were found. These colors contained relatively high amounts of chlorophyll and carotenoid 21 and low concentrations of carotenoid 29 (Table 1). Flowers expressing these new colors contained about one quarter the amount of pigment of $O$. dubium.

In addition to new colors, the $\mathrm{BC}_{1}$ to $O$. dubium segregated new 
Table 1. The number of different meiotic associations at diakinesis and metaphase I within Ornithogalum dubium (0519 $\times 4745)$, O. thyrsoides ( $4230 \times$ Hadeco), and their $\mathrm{F}_{1}$ hybrid. Because of the almost total lack of chromosome pairing between the S-chromosome homeologues, only the L-chromosomes were included in this study. The model of Jackson (1991) was used to predict chiasmata distribution.

\begin{tabular}{|c|c|c|c|c|c|c|c|c|}
\hline \multirow[b]{2}{*}{ Species } & \multirow{2}{*}{$\begin{array}{l}\text { No. } \\
\text { cells }\end{array}$} & \multicolumn{2}{|c|}{ Observed } & \multicolumn{2}{|c|}{ Expected (NR) } & \multicolumn{3}{|c|}{ Expected (R) } \\
\hline & & $\mathrm{cII}^{\mathrm{y}}$ & oll & cII & oII & I & cII & oII \\
\hline O.dubium & 42 & 190 & 20 & 190 & 20 & 86 & 104 & 63 \\
\hline O. thyrsoides & 42 & 203 & 7 & 203 & 7 & 98 & 105 & 56 \\
\hline $\mathrm{F}_{1}$ & 16 & 74 & 6 & 74 & 6 & 34 & 40 & 23 \\
\hline
\end{tabular}

${ }^{\mathrm{z}} \mathrm{NR}=$ normal, nonrandom chiasmata distribution; $\mathrm{R}=$ mutant, random chiasmata distribution. ${ }^{\mathrm{y}} \mathrm{cII}=$ chain bivalent with one chiasmata; $\mathrm{oII}=$ circle bivalent with two chiasmata; $\mathrm{I}=$ univalent. $\mathrm{X}^{2}$ for all expected NR associations, $P=1$.

$\mathrm{X}^{2}$ for all expected $\mathrm{R}$ associations, $\mathrm{P}<0.05$.

Table 2. Carotenoid and chlorophyll content of flowers from $\mathrm{BC}_{1}$ seedlings of $O$. thyroides (4230) $\times O$. dubium (0519) to $O$. dubium $(0519 \times 4745)$. The pigments in $O$. dubium are similar to those found in the $\mathrm{BC}_{1}$ hybrids.

\begin{tabular}{|c|c|c|c|c|}
\hline \multirow[b]{2}{*}{$\begin{array}{l}\text { HPLC } \\
\text { retention } \\
\text { time (min) }\end{array}$} & \multicolumn{4}{|c|}{ Seedlings } \\
\hline & $\begin{array}{c}\text { Dark } \\
\text { orange } \\
\text { (RHS 28B) } \\
\end{array}$ & $\begin{array}{c}\begin{array}{c}\text { Apricot } \\
\text { orange } \\
\text { (RHS 24B) }\end{array} \\
\end{array}$ & $\begin{array}{c}\text { Dark } \\
\text { yellow } \\
\text { (RHS 7A) }\end{array}$ & $\begin{array}{c}\text { Butter } \\
\text { yellow } \\
\text { (RHS 8B) }\end{array}$ \\
\hline \multicolumn{5}{|l|}{$\overline{\text { Carotenoid }}$} \\
\hline 13 & $2^{z}$ & 13 & 3 & 6 \\
\hline 16 & 10 & 13 & 4 & 7 \\
\hline 19 & 8 & 5 & 6 & 8 \\
\hline 21 & 38 & 23 & 11 & 31 \\
\hline 26 & 2 & 9 & 5 & 8 \\
\hline 29 & 30 & 15 & 37 & 8 \\
\hline Chlorophyll & 11 & 22 & 24 & 43 \\
\hline Total $^{y}$ & 2.26 & 0.78 & 3.21 & 0.826 \\
\hline
\end{tabular}

${ }^{z}$ Values are reported as the percentage of total carotenoid/chlorophyll absorption [i.e., yellow flowers (RHS 7A) have $11 \%$ of their pigment present as an unknown carotenoid with a 21 min retention time].

y Total is reported as micrograms of carotenoid and chlorophyll pigments per gram dry weight of flower.

inflorescence types. Tall, intermediate and short inflorescences (Table 3) were found with either tight or loose clusters of flowers. Introgressed plants produced orange flowers on tall inflorescences.

\section{Discussion}

In the early 1900s, scientists at Kew Gardens produced a hybrid Ornithogalum that they named $O . \times$ kewense (Bailey, 1935). The parents were stated to be $O$. thyrsoides and its orange color form var. aureum. Ornithogalum thyrsoides var. aureum is now known as $O$. dubium. Ornithogalum kewense was described as having "bright buff-yellow" flowers. No further information is known about this hybrid. According to R.D. Pienaar (personal communication), the white parent of $O . \times$ kewense was probably not $O$. thyrsoides. He believes that it was most likely the white form of $O$. dubium formerly known as $O$. alticolum.

Van Niekerk and Pienaar (1968) were only able to produce hybrids between $O$. dubium as a seed parent and a form of $O$. thyrsoides collected near Riviersonderend and Swellendan. They were not able to produce hybrids using the typical form of $O$. thyrsoides. Others (Obermeyer, 1978) have also noted that $O$. thyrsoides does not hybridize with $O$. dubium. Roos and Pienaar (1966) separated $O$. thyrsoides into eight cytologically distinct forms based upon which chromosome or chromosomes contained the secondary constriction. Intraspecific hybrids made between the different forms were only partially fertile, typically producing five bivalents and two univalents during metaphase I.

We were not able to produce viable, mature seed from reciprocal crosses of the typical form of $O$. thyrsoides and $O$. dubium. However, seedlings were obtained through in vitro ovule rescue from both reciprocal crosses. Niederwiesser et al. (1990) also experienced difficulty in obtaining seed from conventional interspecific crosses of $O$. dubium and $O$. thyrsoides and developed an in vitro ovule rescue procedure using $O$. dubium. The Niederwiesser protocol involved two media. A high sucrose medium (70 g.liter$\left.{ }^{1}\right)$ was used to mature the embryos, followed by a low sucrose medium (10 g.liter $\left.{ }^{-1}\right)$ to germinate the mature embryos. When immature embryos of $O$. dubium were transferred directly to medium containing low to intermediate levels of sucrose (10 to 30 $\mathrm{g} \cdot$ liter $\left.^{-1}\right)$, malformed seedlings resulted. In Niederwiesser's experiments the high concentrations of sucrose (30 to $70 \mathrm{~g} \cdot$ liter $^{-1}$ ) required to mature the embryos inhibited their germination. Our results differ. We were able to produce normal seedlings from immature embryos matured and germinated on a single medium containing an intermediate (30 g.liter ${ }^{-1}$ ) sucrose concentration. The different requirements suggested by our experiments and Niederwiesser et al. (1990) could be due to the genetic differences 


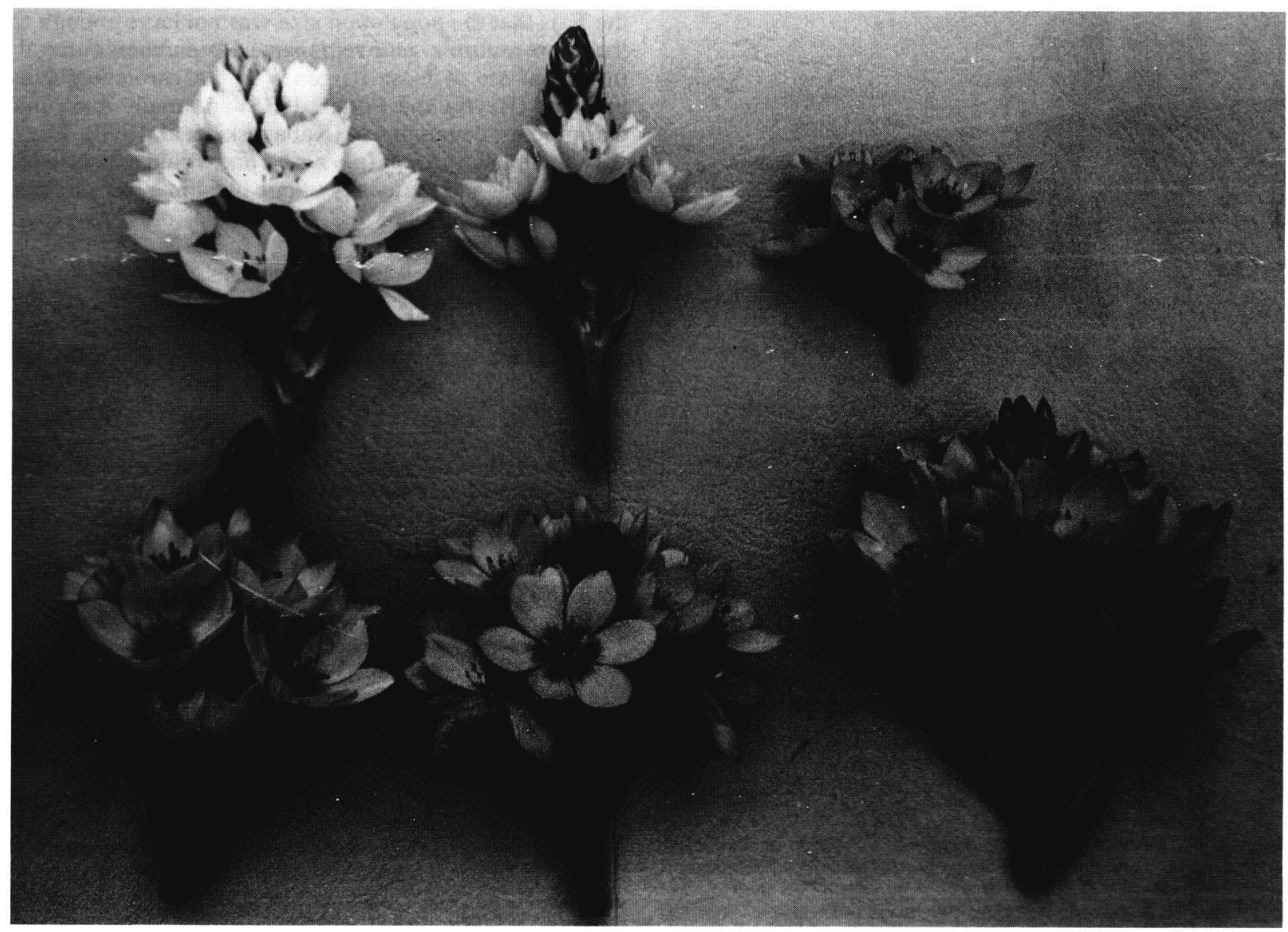

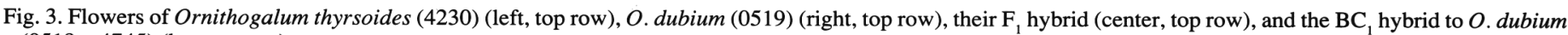
$(0519 \times 4745)$ (bottom row).

between the species used or age of immature ovules. We used older ovules from intraspecific crosses of $O$. dubium, while they used younger ovules from self-pollinated $O$. dubium. We found it extremely difficult to mature and germinate embryos from selfpollinated plants, while intraspecific embryos developed and germinated quite easily. The intraspecific hybrid seedlings were also more vigorous than self-pollinated seedlings.

The primary hybrid between $O$. dubium and $O$. thyrsoides and the reciprocal cross was partially fertile. In contrast, the hybrids produced by Van Niekerk and Pienaar (1968) between the Swellendam form of $O$. thyrsoides and three forms of $O$. dubium were completely sterile and produced no viable pollen. Pienaar (1963) and Roos and Pienaar (1966) likewise found that interspecific hybrid between form 7 of $O$. thyrsoides and $O$. dubium was also sterile. As Van Niekerk and Pienaar (1968) reported, bridges and acentric fragments were also observed in the meiocytes of our $F_{1}$ (Fig. $2 \mathrm{E}$ and F). These structures suggest that the sequence of genes found in some of the chromosomes of one species is inverted relative to those of the other species.

In our partially fertile $F_{1}$, the L-chromosome homeologues formed bivalents composed of chromosomes of unequal lengths. The differences in length is mostly due to S-chromosome translocations to the L-chromosomes. Stedje (1989) has suggested that the most primitive species of Ornithogalum have numerous Schromosomes. By successive unequal translocations, the S-chromosomes contribute segments to the L-chromosomes, resulting in an increasing difference in size between the L and S-chromosomes.

Because of the almost total lack of pairing between the Schromosome homeologues, only the L-chromosomes were included in a pairing analysis. Jackson's (199 1) model for the genetic control of pairing was used to predict chiasmata distribution. The model assumes that if pairing is normal and not influenced by pairing control genes, then the distribution of chiasmata is nonrandom, and no univalents are expected. If pairing is not normal and

Table 3. Flower characteristics of Oranithogalum dubium (0519), $O$. thyrsoides (4230), their $\mathrm{F}_{1}$ hybrid, and the $\mathrm{BC}_{1}$ to $O$. dubium (0519 $\mathrm{x}$ 4745).

\begin{tabular}{llcc}
\hline \hline Species & $\begin{array}{l}\text { Flower } \\
\text { color }\end{array}$ & $\begin{array}{c}\text { Inflorescence } \\
\text { ht } \\
(\mathrm{cm})\end{array}$ & $\begin{array}{c}\text { Pedicel } \\
\text { length } \\
(\mathrm{cm})\end{array}$ \\
\hline O. dubium & Orange & 9 & 1.25 \\
O. thyrsoides & White & 35 & 0.50 \\
$\mathrm{~F}_{1}$ & Light gold & 20 & 0.75 \\
$\mathrm{BC}_{1}$ & Dark orange & 36 & \\
& Apricot orange & 9 & 1.00 \\
& Dark yellow & 16 & 0.50 \\
& Butter yellow & 14 & 0.75 \\
& Near white & 12 & 0.50 \\
\hline
\end{tabular}




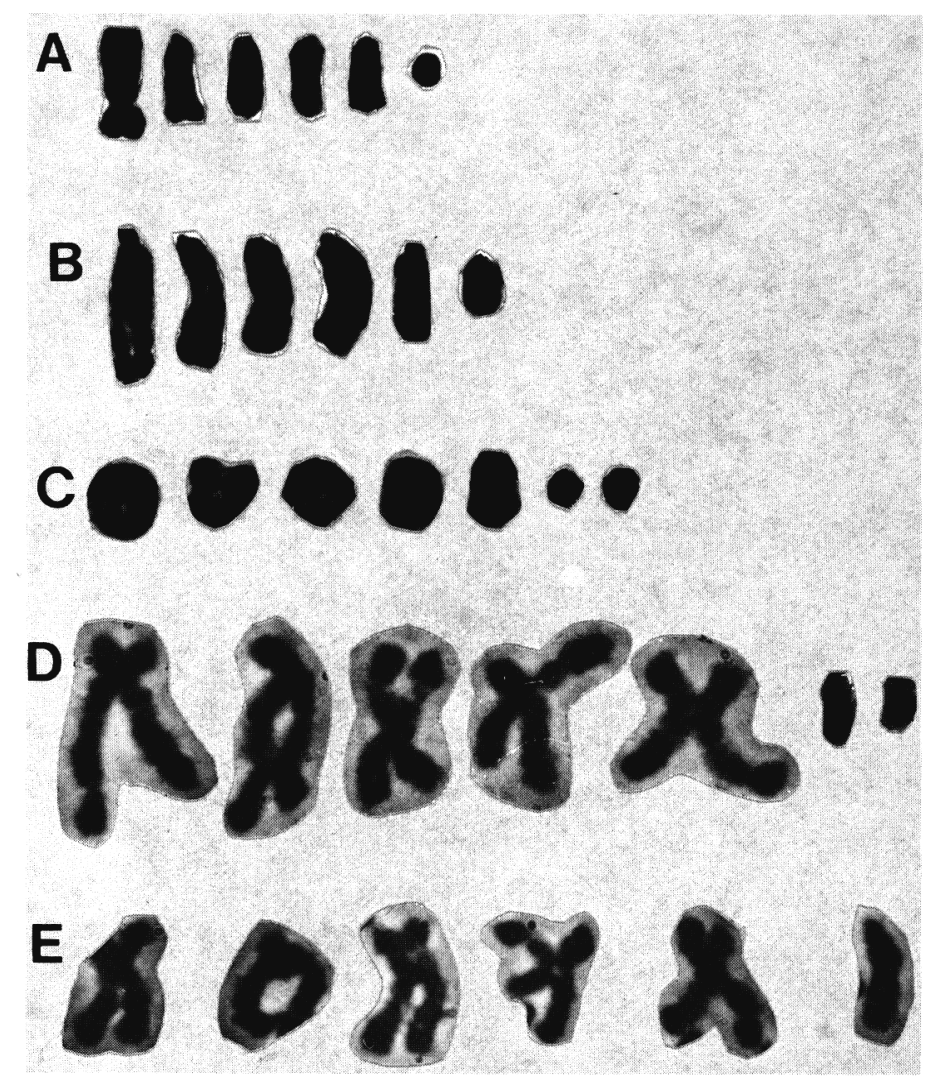

Fig. 4. Chromosomes of Ornithogalum: (A) Haploid karyotype of $O$. dubium (0519). (B) Haploid karyotype of $O$. thyrsoides (4230). (C) Metaphase I chromosomes of the $\mathrm{F}_{1}(O$. dubium $0519 \times$ O. thyrsoides 4230$)$ showing five bivalent. (D) Diakinesis showing the typical five bivalent L-chromosomes and two univalent $\mathrm{S}$-chromosomes. (D) Diakinesis showing the rare five bivalent Lchromosomes and one chain bivalent S-chromosome.

influenced by pairing control genes, then chiasmata distribution is random, and univalents are expected. Our data (Table 1) show no evidence of pairing control genes, because the observed values are identical to the expected values for the nonrandom model.

The $\mathrm{F}_{1}$ between $O$. dubium and $O$. thyrsoides and the reciprocal cross was completely intermediate in flower color and inflorescence habit. In the $\mathrm{F}_{2}$ population, no introgressed segregants were observed. In the $\mathrm{BC}_{1}$ to $O$. dubium introgressed seedlings were found. A simple explanation why parental types were not found in the $\mathrm{F}_{2}$ is that the population size was not large enough to recover these rare multiple-gene segregants. Researchers currently believe that there are at least 10 genes in the carotenoid biosynthetic pathway (Beytia and Porter, 1976) and many more involved in chromoplast development (Kabayaski, et al. 1990). Theoretically, with six linkage groups $(n=x=6)$, one would expect to recover the parental trait at a frequency of one in 64 in a $\mathrm{BC}_{1}$ and one in 4096 in $\mathrm{a}_{2}$. In the largest $\mathrm{BC}_{1}$ population, only 75 progeny were obtained.

Several seedlings from sib-crosses between $\mathrm{BC}_{1}$ plants produced inflorescences of intermediate height $(15 \mathrm{~cm})$, with strong stems, short pedicels, and dark-orange flowers. Several selected seedlings are being propagated for commercial release.

\section{Literature Cited}

Bailey, L. 1935. The standard cyclopedia of horticulture, vol. 2, p. $240 \%$ 2409. MacMillan, New York.

Beytia, E. and J. Porter. 1976. Biochemistry of polyisoprenoid biosynthesis. Annu. Rev. Biochem. 45:113-142.

Braumann, T. and L. Grimme. 1981. Reversed phase high-performance liquid chromatography of chlorophylls and carotenoids. Biochem. Biophys. Acta. 637:8-17.

Jackson, R.C. 1991. Cytogenetics of polyploids and their diploid progenitors, p. 159-180. In: P.K. Gupta and T. Tsuchigu (eds.). Chromosome engineering in plants. Elsvier Sci. Publ., Amsterdam, The Netherlands.

Kobayashi, H., J. Ngerprasirtsiri, and T. Akazawa. 1990. Transcriptional regulation of DNA methylation in plastids during transitional conversion of chloroplasts to chromoplasts. EMBO J. 9:307-313.

Murashige, T. and R. Skoog. 1962. A revised medium for rapid growth and bioassays with tobacco tissue cultures. Physol. Plant. 15:479-497.

Niederwiesser, J.G., H.A. van de Venter, and P.J. Robertse. 1990. Embryo rescue in Ornithogalum. HortScience 25:565-566.

Obermeyer, A. 1978. Ornithogalum: A revision of the southern African species. Bothalia 12:323-376.

Pienaar, R.D. 1963. Sitogenetiese ondersoek in die genus Ornithogalum. I. Inleidende oorsig. J.S. Afr. Bot. 29:111-131.

Roos, T.J. and R.D. Pienaar. 1966. Cytogenetic studies in the genus Ornithogalum. IV. The cytogenetics of inter- and intraspecific crosses involving $O$. thyrsoides Jacq. and O. lacteum Jacq. J.S. Afr. Bot. 32:325333.

Stedje, B. 1989. Chromosome evolution within the Ornithogalum tenuifolium complex, with special emphasis on the evaluation of biomodal karyotypes. Plant Systematics \& Evolution. 166:79-89.

Van Niekerk, H.A. and R.D. Pienaar. 1968. Sitogenetiese ondersoek van ' $\mathrm{n}$ aantal hibriede in die genus Ornithogalum. Proc. 3rd Congr., S. Afr. Genet. Soc. 1966:45-51. 